\title{
Punicalagin Induce the Production of Nitric Oxide and Inhibit Angiotensin Converting Enzyme in Endothelial Cell Line EA.hy926
}

\author{
Ulfat Omar $^{1,2, *}$, Akram Aloqbi ${ }^{1,3}$, Marwa Yousr ${ }^{1}$, Nazlin K. Howell ${ }^{1}$ \\ ${ }^{1}$ Faculty of Health and Medical Sciences, School of Biosciences and Medicine, University of Surrey, UK \\ ${ }^{2}$ Biochemistry Department, Faculty of Science, King Abdulaziz University, Saudi Arabia \\ ${ }^{3}$ Biology Department, Faculty of Science and Arts-Alkamel, University of Jeddah, Saudi Arabia
}

Copyright $\bigcirc 2016$ by authors, all rights reserved. Authors agree that this article remains permanently open access under the terms of the Creative Commons Attribution License 4.0 International License

\begin{abstract}
Introduction: punicalagin, a hydrolysable tannin polyphenol from pomegranate, reported to have a protective effect against many diseases due to its high antioxidant and free radical scavenging activities. Aim, this study investigated the potential antihypertensive activity of punicalagin in human derived EA.hy926 endothelial cell model, via two mechanisms. In first mechanism, punicalagin enhance the nitric oxide production through scavenging reactive oxygen specious (ROS) and activating the endothelial nitric oxide synthase enzyme (eNOS). In second mechanism, punicalagin showed effect activity by inhibiting the angiotensin converting enzyme (ACE). Methods: The effect of different concentrations (1-100 $\mu \mathrm{M})$ of punicalagin on EA.hy926 cells was measured using MTT assay. Induction of ROS was done using Ang II and scavenging activity of punicalagin was assessed by flow cytometer and fluorimeter. NO production was measured in order to determine the effective dose of punicalagin followed by measuring the ability of punicalagin to induce eNOS activity and the enzyme expression by Western blotting cellular $\mathrm{Ca}^{2+}$ concentration and ACE inhibition were also determined. Results: Punicalagin $(1-60 \mu \mathrm{M})$ reduced ROS production in EA.hy926, which induced by added angiotensin II, as shown by flow cytometry and by fluorometry. In addition, at the same concentration the nitric oxide production was increased in a dose-dependent manner due to increased eNOS activation. The activation of eNOS enzyme was promoted by an increase of cellular calcium concentration at the tested concentrations. Examined punicalagin concentrations significantly inhibited ACE activity, possibly due to zinc binding. Conclusion: punicalagin clearly exhibits the potential for reducing hypertensive activity by a dual mechanism of nitric oxide synthase induction by increasing nitric oxide levels, and ACE inhibition.
\end{abstract}

Keywords Dietary Polyphenols, Punicalagin, Endothelial Nitric Oxide Synthase, Oxidative Stress,
Cellular $\mathrm{Ca}^{2+}$ Concentration, $\mathrm{ACE}$

\section{Introduction}

Cardiovascular disease affects the circulatory system (heart, artery and blood vessels). This disease is a leading cause of death all over the world [1]. In the USA, according to the American Heart Association report in 2013, cardiovascular disease (CVD) deaths were 21.42\% [2]. According to the World Health Organization (WHO), in the United Kingdom, CVD was one of the main causes of death in 2011 reaching about $19.77 \%$, while in Saudi Arabia the death rate from CVD was $23.98 \%$ in the same year $[3,4]$.

High blood pressure is a major risk factor for some chronic diseases such as stroke, renal disease, and cardiovascular disease [5]. The regulation of blood pressure is maintained by various physiological systems including the kinin-nitric oxide system (KNOS) and renin-angiotensin system.

High and unregulated production of reactive oxygen species (ROS) is another risk factor for heart disease $[6,7]$. In endothelial cells, enzyme systems involving NADPH oxidase, xanthine oxidase, and the mitochondrial respiratory chain are responsible for ROS production [8]. ROS production needs to be regulated or adverse effects like oxidation may damage cell macronutrients such as proteins, lipids, and nucleic acids. Balance in ROS concentration can be achieved by the antioxidant system that exists in the human body and by taking antioxidant supplements [9]. Moreover, ROS has the ability to oxidize nitric oxide (NO) produced from endothelial cells, leading to endothelial dysfunction and the initiation and development of cardiac disease [10].

Nitric oxide (NO) is known as a relaxing factor because it acts as a vasodilator, increases blood flow, and inhibits platelet aggregation and adhesion [11]. Calcium-dependent 
endothelial NO synthase (eNOS) is one of the important factors responsible for the production of $\mathrm{NO}$ in endothelial cells. Increased levels of NO in the endothelial cells are often due to the increased protein expression of the eNOS enzyme or by scavenging the ROS produced within the cells $[12,13]$.

In renin-angiotensin system, angiotensin II is produced from angiotensin I by the catalytic effect of angiotensin converting enzyme; this is higher than normal levels in patients with hypertension [14, 15]. Angiotensin II acts as vasoconstrictor, increasing blood pressure. For this reason, inhibition of ACE activity is a pharmacological target for the treatment of hypertension [16]. The ACE enzyme has a $\mathrm{Zn}^{2+}$ ion in its two active sites [17]. Substrate binding and catalysis of ACE indicate the mechanism of $\mathrm{Zn}^{2+}$ ion [18]. One of the mechanisms of ACE inhibitors is the ability to bind the $\mathrm{Zn}^{2+}$ ion [19].

Several research groups have reported a significant interaction between biological systems and dietary polyphenols from vegetables and fruits, that may lead to beneficial anticancer [20, 21], anti-inflammatory [22], antioxidant (ROS scavenging or metal chelating) [23], and antibacterial properties [24]. Pomegranate contains a high quantity of different polyphenols e.g. tannins, ellagic tannins, anthocyanins, catechins, gallic, and ellagic acid [25, 26] including punicalagin (of the ellagitannin class). There are very few studies on punicalagin to date. Therefore, the effect and mechanism of punicalagin as an anti-hypertensive compound was investigated in the EA.hy926 cell line for two pathways.

\section{Materials and Methods}

\subsection{Materials}

The human endothelial-like immortalized cell line Ea.hy926 was kindly donated by Dr. Bodman-Smith University of Surrey, UK. Ethylene glycol tetraacetic acid (EGTA), hippuryl-histidyl-leucine (H-H-L) and angiotensin II were obtained from Sigma-Aldrich Chemical Co, Poole, UK. Griess Reagent Kit for nitrite quantitation, Hanks buffer saline solution (HBSS) buffer with calcium and magnesium, $o$-phthaldialdehyde, high purity, fura-2, AM, dihydroethidium dye, foetal bovine serum (FBS), trypsin-EDTA solution, Dulbecco's Modified Essential Medium (DMEM), penicillin were obtained from Invitrogen, Paisley, UK. Antibody eNOS and $\beta$-actin mouse mAb were purchased from cell signaling technology, Hertfordshire, UK. EnzyChrom $^{\mathrm{TM}}$ Nitric Oxide Synthase Assay Kit was obtained from Universal Biological, Cambridge, UK. Chemiluminescent Kit-Anti-Rabbit, Chemiluminescent Kit-Anti-Mouse, NuPAGE® Novex 4-12\% Bis-Tris Gel 1.0 $\mathrm{mm}\left(15\right.$ well), Novex ${ }^{\circledR}$ Sharp Pre-stained Protein Standard $-2 \times 250 \mu 1$, Invitrolon ${ }^{\mathrm{TM}}$ PVDF/Filter Paper Sandwiches, NuPAGE $®$ Transfer Buffer (20X) (1 L), NuPAGE® MOPS SDS Buffer Kit (for Bis-Tris Gels), NuPAGE ${ }^{\circledR}$ Sample Reducing Agent $(10 \mathrm{X})(250 \mu \mathrm{l})$ and NuPAGE ${ }^{\circ}$ LDS
Sample Buffer (4X) (10 ml) were obtained from Invitrogen, Paisley, UK. Fixer and developer solutions champion am fix were obtained from First Call Photography, West Monkton, UK.

\subsection{Methods}

\subsubsection{Cell Viability and Nitric Oxide (NO) Release}

The EA.hy926 cell line was seeded in DMEM with high glucose content $(4.5 \mathrm{~g} / \mathrm{L})$, and supplemented with $10 \%$ FBS and $5 \%$ penicillin. Different punicalagin concentrations $(1-100 \mu \mathrm{M})$ were tested on Ea.hy926 cells to measure the cell viability and nitric oxide (NO) production. Briefly, Ea.hy926 cells were seeded into 96 well tissue culture plates at a density of $1 \times 10^{4}$ cells/200 $\mu 1$ DMEM serum media. Once the cells reached $60-70 \%$ confluence, they were treated with punicalagin for 12,24 , or 48 hours. Different incubation times were tested to determine the optimal time for nitrite production, as a marker of nitric oxide production and cell viability. Nitrite levels in the treated cell supernatant were measured by the Griess kit according to the Griess kit instructions and cell viability was measured by MTT assay, at each experimental time.

Cells pretreated with different concentrations of punicalagin were incubated with $20 \mu \mathrm{l}$ of MTT dye $(5 \mathrm{mg} / \mathrm{ml}$ PBS $)$ at $37{ }^{\circ} \mathrm{C}$ and $5 \% \mathrm{CO}_{2}$ to measure cell viability after different incubation times. At the end of each experimental time, the culture medium was aspirated and $100 \mu \mathrm{l}$ of DMSO was added to each well for 30 seconds at room temperature to dissolve the formazan crystals. The purple colour produced was measured at $492 \mathrm{~nm}$ using a plate reader (Boehring CO, Marburg, Germany).

\subsubsection{Measurement of ROS by Flow Cytometry}

Dichlorofluorescein dye (non-fluorescent $\mathrm{CM}-\mathrm{H}_{2}$ DCFDA) has the ability to diffuse through the cell membrane [27]. The fluorescence intensity is proportional to the ROS content [27]. The ROS level in the Ea.hy926 cell line was determined by flow cytometry, using $\mathrm{CM}-\mathrm{H}_{2} \mathrm{DCFDA}$ dye after incubation with $1,20,40$, and $60 \mu \mathrm{M}$ punicalagin. Ea.hy926 cells $1 \times 10^{6}$ cells $/ \mathrm{ml}$ were exposed to different punicalagin concentrations for 24 hours after reach $(60-70 \%)$ confluence. Half of pre-treated cells were exposed to $10 \mathrm{nM}$ angiotensin II for 1 hour, while the other half were left untreated. The cells were trypsinised, washed and in re-suspended $2 \mathrm{ml}$ HBSS. Cells were then incubated with $5 \mu \mathrm{M} \mathrm{CM}-\mathrm{H}_{2} \mathrm{DCFDA}$ (prepared in DMSO) for 30 minutes at $37{ }^{\circ} \mathrm{C}$ and $5 \% \mathrm{CO}_{2}$. DCFDA florescence was then measured using a BD FACSCanto Flow cytometer (California, USA). At least 10,000 events were acquired in the gated regions using an emission wavelength of $520 \mathrm{~nm}$.

\subsubsection{Measurement of ROS by Fluorometry}

The florescent dye, dihydroethidium can penetrate the cell membrane and is oxidized by superoxide radicals to form 2-hydroxyethidium; a red fluorescent product [28]. This 
interacts with DNA to enhance intracellular fluorescence [29, 30]. Ea.hy 926 cells $1 \times 10^{6}$ cells $/ \mathrm{ml}$ was exposed to different punicalagin concentrations $(1,20,40$ and $60 \mu \mathrm{M})$ for 24 hours after reach $60-70 \%$ confluence. After 24 hours, one group of treated cells was incubated with angiotensin II (10 $\mathrm{nM}$ ) for 1 hour and another group was left untreated (control). All cells were then washed with HBSS buffer. Cells were covered with $3 \mathrm{ml} \mathrm{HBSS}$ buffer and incubated with $25 \mu \mathrm{M}$ of DHE dye for 30 minutes at $37{ }^{\circ} \mathrm{C}$ and $5 \% \mathrm{CO}_{2}$. HBSS buffer was discarded and the cells were scraped from the flask with $1 \mathrm{ml}$ cold methanol. The cell suspension was sonicated and filtered through a $0.22 \mu \mathrm{M}$ membrane filter. The 2-hydroxyethidium was detected by fluorimetry (Varian, USA) with excitation and emission wavelengths of $480 \mathrm{~nm}$ and $580 \mathrm{~nm}$, respectively.

\subsubsection{Determination of Cellular Calcium Concentration by Fluorescence Method}

Intracellular calcium concentrations were measured by fluorometry after loading the cells with fura-2/AM dye. Free intracellular calcium will bind with the membrane diffusible fluorescent dye fura-2/AM [31]. Briefly, Ea.hy926 cells were cultured in $25 \mathrm{~cm}^{2}$ flasks at $1 \times 10^{6}$ cells $/ \mathrm{ml}$ and exposed to different concentration $(1,20,40$ and $60 \mu \mathrm{M})$ after they reached $60-70 \%$ confluence. Following 24 hours incubation, cells were loaded with $5 \mu \mathrm{M}$ fura-2/AM dye and incubated for 45 minutes at $37{ }^{\circ} \mathrm{C}$ and $5 \% \mathrm{CO}_{2}$. Consequently, the dye was removed and the cells were washed and scraped from the flask with $2 \mathrm{ml} \mathrm{HBSS}$ buffer. The calcium concentration was detected by fluorometry (Varian, USA) with excitation and emission wavelengths of $340 \mathrm{~nm}$ and $510 \mathrm{~nm}$, respectively. Ethyleneglycoltetraacetic acid (EGTA) at $1 \mathrm{mM}$ was used as negative control instead of punicalagin.

\subsubsection{Determination of Endothelial Nitric Oxide Synthase Enzyme (eNOS) Activity in the Ea.hy926 Cell Line}

Ea,hy926 Cells treated with different concentrations of punicalagin $(1,20,40$ and $60 \mu \mathrm{M})$ for 24 hours, were lysed as follows. After this incubation, the cells were trypsinized and the resulting cell suspension centrifuged at $1500 \times g$ for 3 minutes with $5 \mathrm{ml}$ PBS to wash. Supernatants were removed and the cell pellets were lysed by adding $300 \mu$ of lysis buffer (Sigma Aldrich Chemical Company). The lysis cell was kept it on ice for 20 minutes and then stored them at $-20^{\circ} \mathrm{C}$ until eNOS activity was measured. EGTA $(1 \mathrm{mM})$ was used as a negative control in place of punicalagin.

eNOS synthase activity was measured using a nitric oxide synthase assay colorimetric kit (Bioassay System, ENOS-100) According to the manufacturer's instructions.

\subsubsection{Assessment of eNOS Expression by Western Blot}

Ea,hy926 cells were treated with $1,20,40$ and $60 \mu \mathrm{M}$ punicalagin and incubated for 24 hours and lysed lysis buffer (Sigma Aldrich Chemical Company)as described in 2.2.5 and stored at $-80^{\circ} \mathrm{C}$ until protein determination and western blot experiment were carried out. The protein concentration for each sample was measured by Bradford method using
BioRad assay [32] following the manufacturer's instructions. An Invitrogen NuPAGE 4-12\% Bis-Tris gel was used for protein electrophoresis. The proteins were then transferred to a polyvinyl difluoride (PVDF). The results were visualized by chemiluminescence using Amersham film.

\subsubsection{Measuring ACE Activity in Ea.hy926}

Angiotensin converting enzyme activity was measured in the Ea.hy926 cell line after 24 hours of exposure to different concentrations of punicalagin $(1,20,40$ and $60 \mu \mathrm{M})$ using a modified fluorometric method [33]. Briefly, Ea.hy926 cells were seeded to confluence in $25 \mathrm{~cm}^{2}$ flasks $\left(1 \times 10^{6}\right.$ cells $\left./ \mathrm{ml}\right)$ and then incubated with punicalagin $(1,20,40$ and $60 \mu \mathrm{M})$ for 24 hours. Treated cells were washed three times with $3 \mathrm{ml}$ HBSS buffer. The cells were scraped from the flask with 1 $\mathrm{ml}$ HBSS and frozen at $-20{ }^{\circ} \mathrm{C}$ until assayed. For the assay, frozen cells were thawed and sonicated then $20 \mu \mathrm{l}$ samples were added to $80 \mu \mathrm{l}$ of H-H-L ( $5 \mathrm{mM}$ prepared in HBSS buffer) and incubated at $37{ }^{\circ} \mathrm{C}$ for 3 hours. The incubated cells were then mixed with $1.4 \mathrm{ml} \mathrm{NaOH}(0.5 \mathrm{~N})$ to stop the reaction. The fluorescent dye, $O$-phthaldialdehyde (100 $\mu \mathrm{l}$ of $10 \mathrm{mg} / \mathrm{ml}$ in methanol) was used to detect the histidyl-leucine reaction product. The reagents were incubated for 5 minutes at room temperature followed by the addition of $250 \mu \mathrm{l}$ of $\mathrm{HCl}(6 \mathrm{~N})$. A was used to measure the fluorescence of the samples was measured by fluorometry (Varian, USA), using an excitation wavelength of $365 \mathrm{~nm}$ and an emission wavelength of $495 \mathrm{~nm}$. Captopril $(1 \mu \mathrm{M})$ was used as a positive control.

ACE inhibition $\%=($ fluorescence of untreated cellfluorescence of treated cell)/( fluorescence of untreated cell) $\times 100$

\subsection{Statistical Analyses}

All experiments were performed at least in triplicate. For the 96-well microtiter tissue culture plates, 4 replicate wells were used per category. The data were analyzed by Graphpad Prism version 6. For significant differences between control and experimental values, the P-value between groups was determined by one-way analysis of variance followed by Bonferroni test. The significance level was set at $\mathrm{P} \leq 0.05$.

\section{Results}

\subsection{Cell Viability and NO Production}

Cell viability and nitric oxide production was measured over a time course to determine the optimal experimental exposure time. The data in (Figure 1 A) show that cell viability increased significantly $(p \leq 0.05)$ after treatment with $1,20,40$, and $60 \mu \mathrm{M}$ punicalagin for 12 hours, but that NO production was similar compared with the untreated control (Figure $1 \mathrm{~B}$ ). In contrast, there was a significant decrease in cell viability at 80 and $100 \mu \mathrm{M}$ punicalagin 
concentrations $(\mathrm{p}<0.0001)$ with a corresponding significant decrease in NO production at 12 hours $(\mathrm{p}<0.0001)$. After 24 hours incubation time with 1-60 $\mu \mathrm{M}$ punicalagin, cell viability and NO production were significantly increased ( $\mathrm{p}$ $\leq 0.05$ ) compared with untreated cells (control) as shown in (Figures $1 \mathrm{C}$ and D). As for the 12-hours incubation, 80 and $100 \mu \mathrm{M}$ punicalagin caused a significant decrease in cell viability and NO production compared with untreated cells $(\mathrm{p} \leq 0.05)$.

After 48 hours incubation significant decreases in cell

A

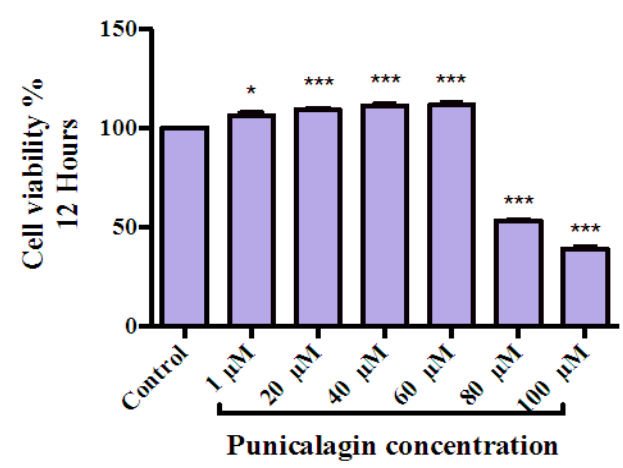

C
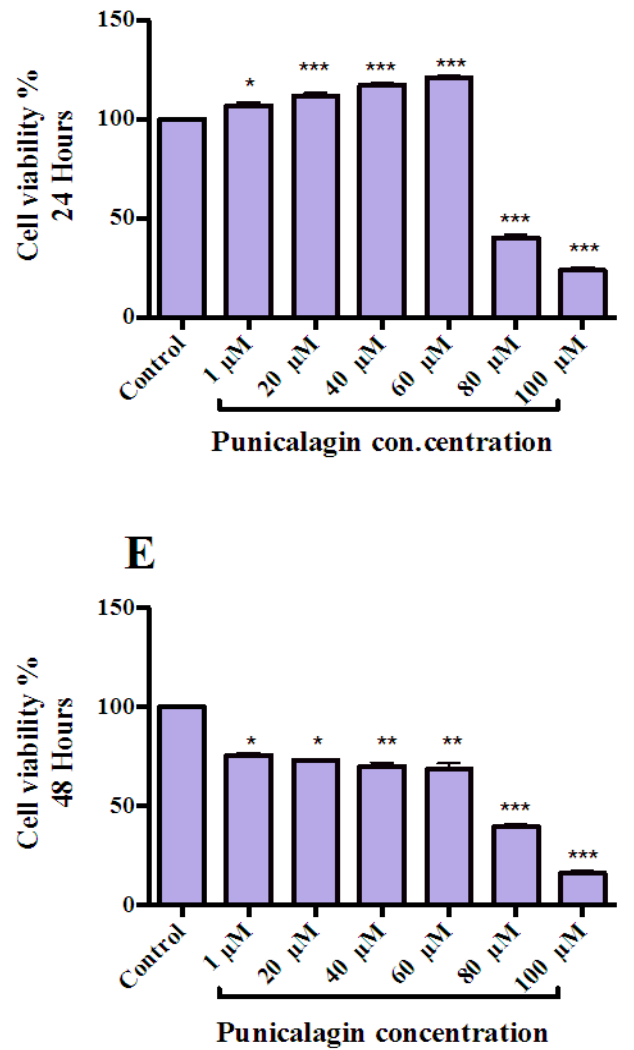

viability $(\mathrm{p} \leq 0.05)$ and $\mathrm{NO}$ production $(\mathrm{p}<0.001)$ were observed at all punicalagin concentrations (1, 20, 40, 60, 80 and $100 \mu \mathrm{M})$ (Figures $1 \mathrm{E}$ and F). Based on the above cell viability and NO production results, punicalagin concentrations in the range $1-60 \mu \mathrm{M}$ were selected for exposure to cells for 24 hours in future experiments because higher punicalagin concentrations $80-100 \mu \mathrm{M}$ produced a toxic effect on Ea.hy926 cells. The significantly enhanced release of NO due to the activation of eNOS enzyme is described below in section 3.3.

\section{B}

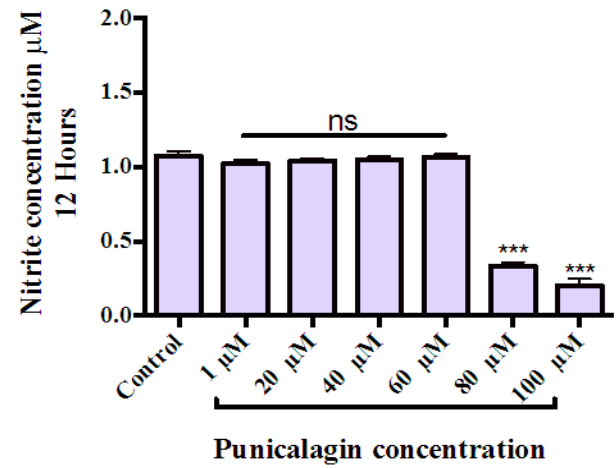

D
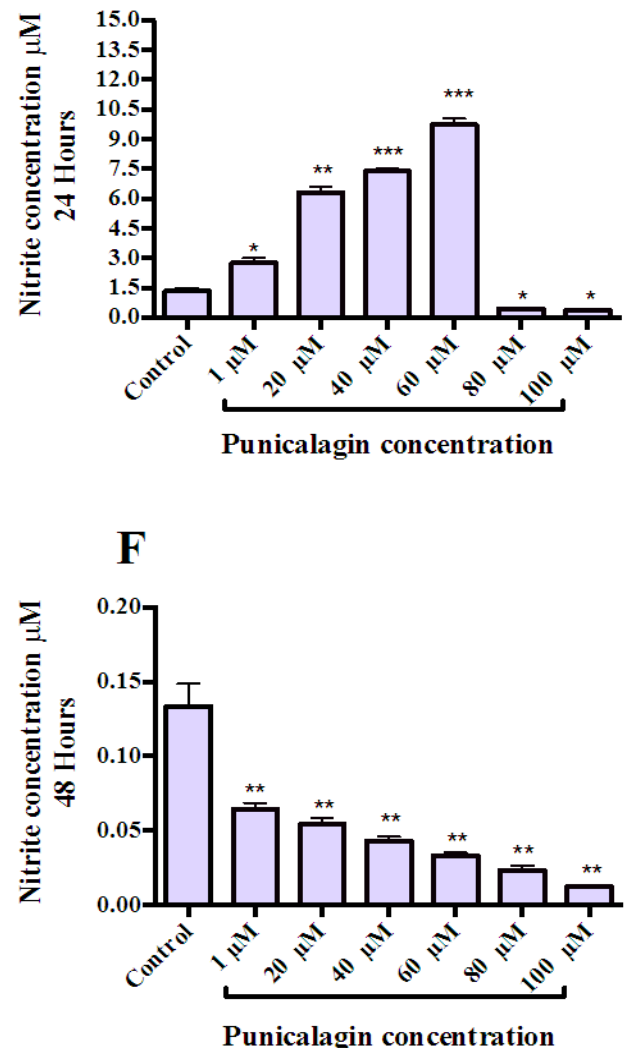

Figure 1. Cell viability and NO production after exposure of Ea.hy926 cells to different concentrations of punicalagin (1-100 $\mu \mathrm{M})$ for 12,24 and 48 hours. A,C and E represent Cell viability; B, D and F represent NO production (nitrite concentration used as a marker). Data represent mean \pm SD of three individual experiments. Comparisons of means were made using a one-way ANOVA followed by Bonferroni's test $(*=\mathrm{p}<0.05 ; * *=\mathrm{p}<0.001 ; * * *=\mathrm{p}<$ 0.0001 versus control). 


\subsection{Measurement of ROS by Flow Cytometry and Fluorometry}

Angiotensin (Ang) II has the ability to stimulate ROS production in endothelial cells through activation of a redox-sensitive signaling system. In an endothelial cell line, NADPH oxidase was considered as a source of ROS, responding to Ang II with the donation of an electron to reduce a molecule of oxygen to produce the superoxide anion, $\mathrm{O}_{2}{ }^{\bullet-}$ [34]. ROS production in the Ea.hy926 cell line, treated with different concentrations of punicalagin for 24 hours, in the absence of Ang II stimulation, was not significantly different to ROS production in cells not treated with punicalagin. This was true using either flow cytometry (Figure $2 \mathrm{~A}$ ) or fluorimetry (Figure $3 \mathrm{~A}$ ) as the ROS determination method.

The ability of different concentrations of punicalagin added to Ea.hy296 cells for 24 hours to reduce ROS production was assessed by flow cytometry after treating cells with $10 \mathrm{nM}$ Ang II for 1 hour (Figure $2 \mathrm{~B}$ ). As described in the methods section, the non-fluorescent $\mathrm{CM}-\mathrm{H}_{2} \mathrm{DCFDA}$ dye is converted to fluorescent DCF in the presence of ROS. The cells treated with Ang II showed a significant decrease

A

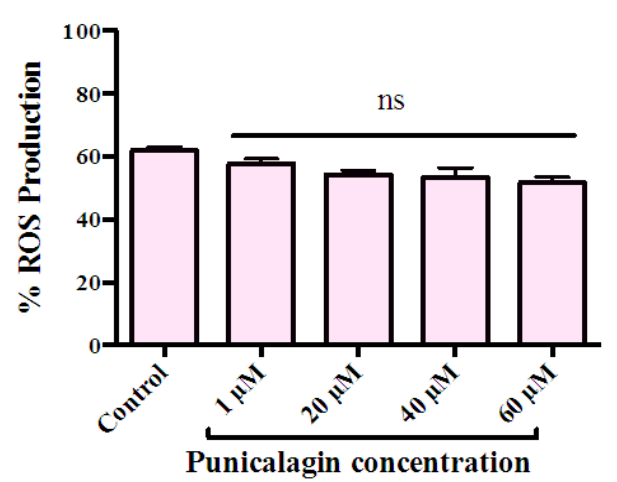

in fluorescence intensity as the concentration of punicalagin increased compared with cells treated with Ang II alone (positive control) (Figure $2 \mathrm{~B}: \mathrm{p} \leq 0.001$ ). The percent inhibition was $75,60,51,49$ and $48 \%$ for the positive control, and 1, 20, 40 and $60 \mu \mathrm{M}$ punicalagin, respectively.

The results were confirmed by a second method, measuring the conversion of DHE 2-hydroxyethidium in the presence of ROS, by fluorimetry (Figure 3 B). The fluorescence intensity in Ea.hy926 cells incubated for 24 hours with punicalagin $(1,20,40$ and $60 \mu \mathrm{M})$ and then treated with $10 \mathrm{nM}$ Ang II also decreased in a dose-dependent manner compared with cells treated with Ang II only (positive control). The fluorescence intensity was $0.83,0.59,0.54$, 0.48 and 0.46 for positive control, and $1,20,40$ and $60 \mu \mathrm{M}$ punicalagin, respectively. These findings are in contrast with cells not stimulated with Ang II, in which no significant difference was found in ROS levels between punicalagin-treated cells and control by flow cytometry or fluorescence methods (Figure $2 \mathrm{~A}$ and $3 \mathrm{~A}$, respectively). These results illustrate that punicalagin has the ability to scavenge ROS and thereby protect cellular macromolecules from ROS-mediated damage.

\section{$\mathbf{B}$}

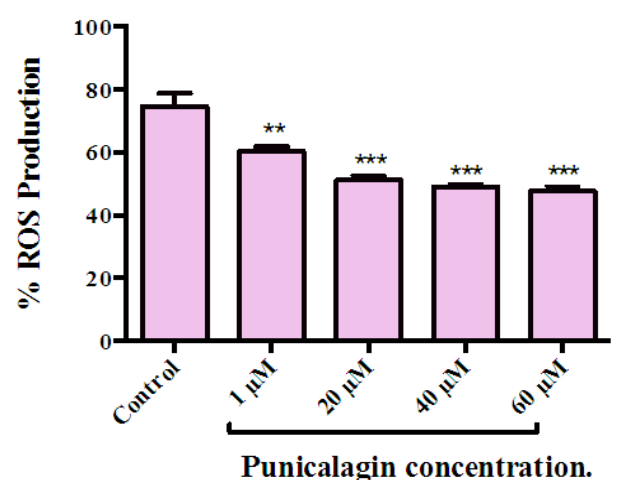

Figure 2. ROS production measurement by flow cytometery in the Ea.hy 926 cell line incubated with different punicalagin concentrations with/without 10 $\mathrm{nM}$ angiotensin II for 1 hour. A) ROS production in the Ea.hy926 cell line treated with different punicalagin concentrations (1-60 $\mu \mathrm{M})$; B) pre-treated cells with punicalagin incubated with $10 \mathrm{nM}$ angiotensin II for 1 hour. Values are mean $\pm \mathrm{SD}, \mathrm{n}=3$. Comparisons of means were made using a one-way ANOVA followed by Bonferroni's test (ns= non significant, $* *=\mathrm{p}<0.001$ and $* * *=\mathrm{P}<0.0001$ when compared with control).

A

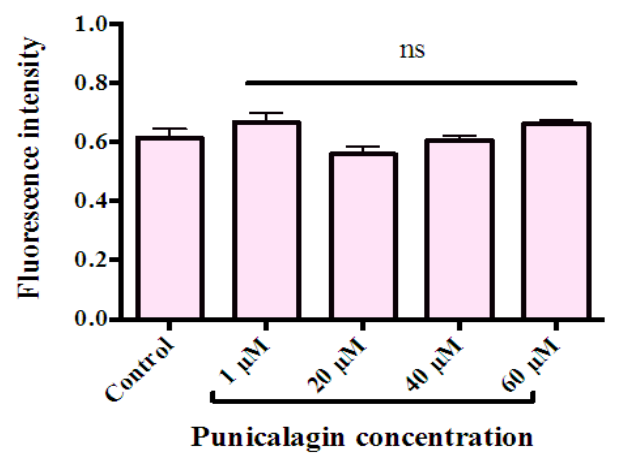

B

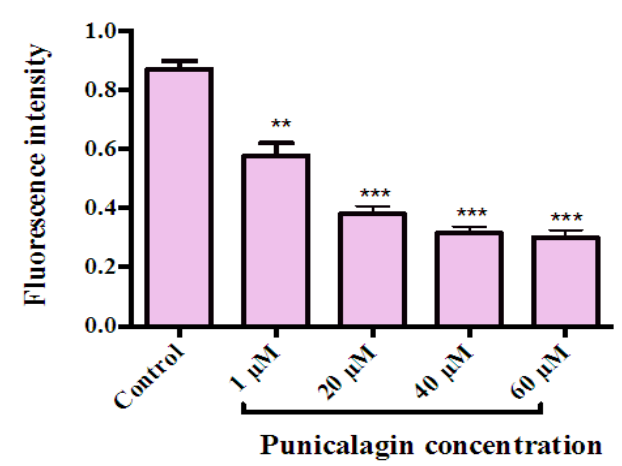

Figure 3. ROS production measurement by DHE fluorescence method in the Ea.hy 926 cell line incubated with different punicalagin concentrations with/without $10 \mathrm{nM}$ angiotensin II for 1 hour. A) ROS production in the Ea.hy926 cell line treated with different punicalagin concentrations (1-60 $\mu \mathrm{M})$; B) pre-treated cells with punicalagin incubated with $10 \mathrm{nM}$ angiotensin II for 1 hour. Values are mean $\pm \mathrm{SD}, \mathrm{n}=3$. Comparisons of means were made using a one-way ANOVA followed by Bonferroni's test (ns $=$ non significant, $* *=\mathrm{p}<0.001$ and ${ }^{* * *} \mathrm{P}<0.0001$ when compared with control). 

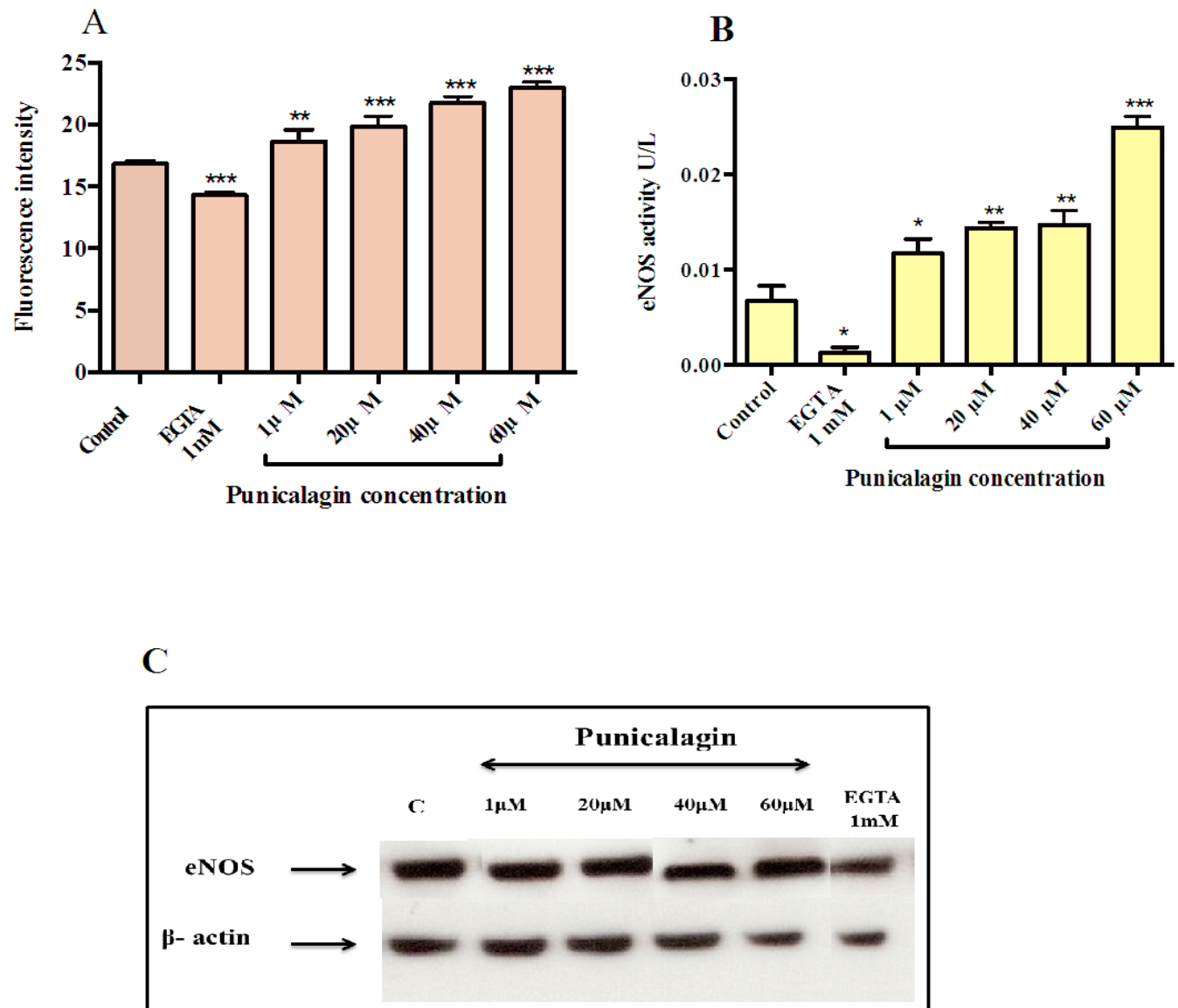

Figure 4. A) Calcium concentration in Ea.hy926 cells exposed to punicalagin $(1-60 \mu \mathrm{M})$ for 24 hours. Calcium concentration was increased in a dose-dependent manner. Fura 2/AM dye was used to measure calcium concentration. B) Effect of different concentrations of punicalagin (1-60 $\mu$ M) incubated for 24 hours on eNOS activity in the Ea.hy926 cell line. C) Western blot of eNOS expression in Ea.hy926 cells treated with different punicalagin concentrations. Protein was extracted from Ea.hy926 cells after treatment with 1-60 $\mu \mathrm{M}$ punicalagin for 24 hours. EGTA 1 mM incubated for 3 hours was used as a negative control. Data represent mean $\pm \mathrm{SD}$ of more than three experiments. Comparisons of means were made using a one-way ANOVA followed by Bonferroni's test $(*=\mathrm{p}<0.05 ; * *=\mathrm{p}<0.001$; and $* * *=\mathrm{p}<0.0001)$.

\subsection{Determination of Cellular Calcium Concentration, eNOS Activity and Expression}

Different concentrations of punicalagin $(1,20,40$ and 60 $\mu \mathrm{M})$ exposed to Ea.hy926 cell line for 24 hours caused a significant dose-dependent increase in intracellular $\mathrm{Ca}^{2+}$ concentration $\mathrm{p}<0.001$ (Figure $4 \mathrm{~A}$ ). Since eNOS activity is dependent on $\mathrm{Ca}^{2+}$, the cytoplasmic $\mathrm{Ca}^{2+}$ concentration was investigated in response to different punicalagin concentrations. EGTA (a $\mathrm{Ca}^{2+}$ inhibitor) was used as the negative control.

This study demonstrates that the punicalagin from pomegranate $(1-60 \mu \mathrm{M})$ produced a significant increase in calcium concentration in EA.hy926 cell line after incubation for 24 hours. Polyphenols can affect intracellular $\mathrm{Ca}^{2+}$ store and release it or increase the entrance of $\mathrm{Ca}^{2+}$ through the cell membrane [35]. This suggestion could explain the significant induction of $\mathrm{Ca}^{2+}$ concentration by different punicalagin concentrations in the endothelial cell line $(\mathrm{p}<$ $0.001)$.

The effects of punicalagin at different concentrations (1, $20,40$, and $60 \mu \mathrm{M})$ on the activation of the eNOS enzyme were determined in Ea.hy926 cells after 24 hours exposure time. As shown in Figure $4 \mathrm{~B}$, punicalagin caused a significant increase in eNOS enzyme activity that was dose-dependent $p \leq 0.05$. EGTA $(1 \mathrm{mM})$ was used as the negative control.

Western blot analysis using a specific antibody against eNOS revealed no change in eNOS protein expression in Ea.hy926 cells treated with punicalagin compared with untreated control cells (Figure $4 \mathrm{C}$ ). The calcium concentration for $1 \mathrm{mM}$ EGTA (negative control) was significantly decreased $(\mathrm{p} \leq 0.05)$; therefore, the protein expression level of eNOS enzyme was down regulated and eNOS enzyme activity decreased. Punicalagin may increase eNOS activity via eNOS phosphorylation, which is enhanced by the activation of redox-sensitive phosphatidylinositol-3 (PI3)/ protein kinase B (AKT) pathways [36, 37].

\subsection{Measuring ACE Activity in Ea.hy926 Cells}

In this study, incubation of Ea.hy926 with different concentrations of punicalagin $(1,20,40$ and $60 \mu \mathrm{M})$ for 24 hours caused significant and dose-dependent inhibition of ACE activity compared with the control (Figure 5) $(\mathrm{P}<$ $0.0001)$. The inhibition percent was $62,30,41,44$ and $51 \%$ 
achieved from $1 \mu \mathrm{M}$ captopril, and 1, 20, 40 and $60 \mu \mathrm{M}$ punicalagin, respectively.

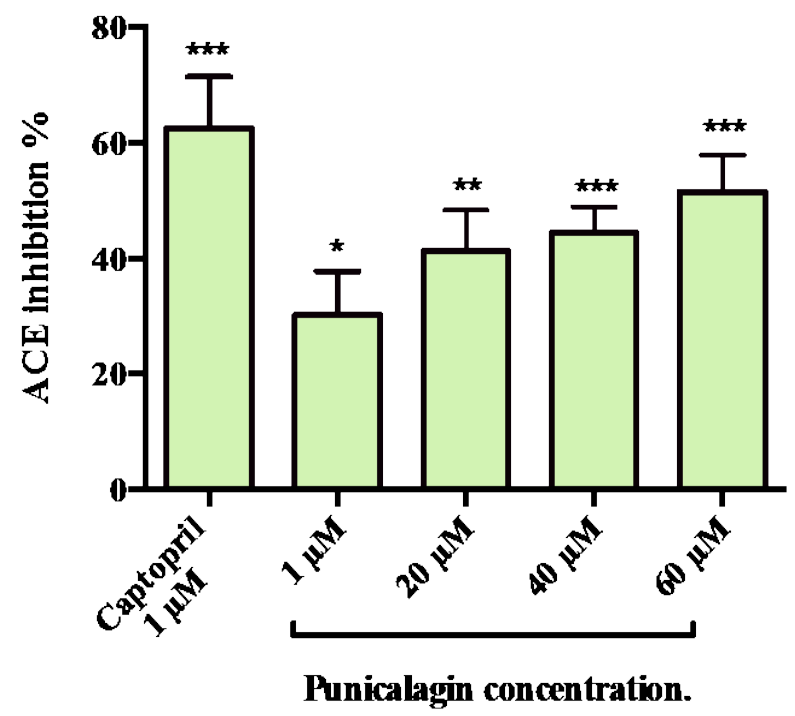

Figure 5. ACE inhibition activity in Ea.hy926 cell exposed to punicalagin $(1-60 \mu \mathrm{M})$ for 24 hours. Data represent mean \pm SD of more than three experiments. Comparisons of means were made using a one-way ANOVA followed by Bonferroni's test $\left(*=p<0.05,{ }^{* *} p<0.001\right.$ and $\left.* * *=p<0.0001\right)$. Captopril was used as a positive control.

\section{Discussion}

Several studies have shown the effect of polyphenols to produce NO in agreement with our findings. EA.hy296 cell line incubated with red wine polyphenol extract (100-600 $\mu \mathrm{g} / \mathrm{ml}$ for 18 hours produced a significant increase in NO production [38]. Dihydrocaffeic acid (caffeic acid metabolite) at different concentrations $(0-200 \mu \mathrm{M})$ significantly increased the production of $\mathrm{NO}$ after being added to EA.hy926 cells for 18 hours in a dose-dependent manner [39]. Another study was performed on NO production after incubating the bovine pulmonary artery endothelial cell line with 50 and $100 \mu \mathrm{M}$ pomegranate juice for 24 and 48 hours. The observed result showed an increased NO production [40]. Punicalagin and $o$-galloyl punicalagin extracted from Terminalia calamansanai plant leaves $(50 \mu \mathrm{M}$ each $)$ produced a significant increase in NO production in bovine aortic cell line [41]. NO production was also significantly increased in a dose- dependent manner after incubating the EA.hy926 cell line for 24 hours with different polyphenols (resveratrol, epicatechin gallate and epigallocatechin gallate) [42]. Different concentrations (0.1-10 $\mu \mathrm{M})$ of polyphenols extracted with $70 \%$ acetone from black currant were exposed to EA.hy 926 cell line for 10 minutes and produced a significant increase in NO productionin a dose-dependent manner [36].

Numerous studies have been conducted on endothelial cell lines to examine the effect of polyphenols as ACE inhibitors. Black tea, green tea and rooibos tea, epicatechin, epigallocatechin, epicatechin gallate and epigallocatechin gallate were incubated with HUVEC cell line at different concentrations for 10 minutes. All experimental components inhibited the activity of ACE at all concentrations except rooibos tea. Rooibos tea did not contain any catechin compounds [43]. In 2009, another study was performed on HUVEC cell line to investigate the inhibition of ACE enzyme after exposure to aqueous phenolic extract from Vaccinium myrtillus (bilberry). The bilberry extract contained several polyphenols such as quercetin, stillbene, resveratrol, ferulic acid and coumaric acid; these components $(0.000625-0.1 \mathrm{mg} / \mathrm{ml})$ significantly inhibited ACE activity in a dose dependent manner in HUVEC cell line treated for 10 minutes [16].

Aviram and Dornfeld (2001) found that serum ACE enzyme activity was significantly inhibited by $36 \%$ in seven-hypertensive patients who consumed pomegranate juice for 2 weeks. Each treated patient's serum was incubated with pomegranate juice $(50-350 \mu \mathrm{M})$ for 15 minutes at $37{ }^{\circ} \mathrm{C}$. The enzyme activity was significantly inhibited in a dose dependent manner [14]. Thus, all the previous research results show similar effects to punicalagin in the present study as an inhibitor for ACE activity on EA.hy926 cell line which is a new finding. The ACE inhibitory activity may be due to metal chelation by punicalagin as zinc ion is present in the active site of ACE.

As reported previously from several in vitro studies, the presence of the $\mathrm{OH}$ group in phenolic compounds plays an important role in scavenging ROS $[44,45,46]$. The Chinese medicine, Seabuckthorn, contains different flavonoids e.g. quercetin, isorhamnetin and kaempherol. Seabuckthorn at different concentrations $(9.38-37.5 \mu \mathrm{g} / \mathrm{ml})$ and $15 \mu \mathrm{g} / \mathrm{ml}$ quercetin was incubated with EA.hy926 cell line for 20 minutes separately before adding $100 \mu \mathrm{g} / \mathrm{ml}$ oxidized LDL as a ROS inducer for a 24 hours incubation time. A protective effect against superoxide anion in EA.hy926 cells was found [47]. ROS production was significantly decreased in liver cell line (HepG2) exposed to different concentrations of quercetin and rutin $(1-100 \mu \mathrm{M})$ for 24 hours followed by incubation with $200 \mu \mathrm{M} \mathrm{H}_{2} \mathrm{O}_{2}$ for 3 hours [48]. Pomegranate juice, concord juice and blueberry juice antioxidant activities were examined and showed scavenging of superoxide anion and protection of NO destruction from ROS action. Pomegranate juice, diluted 6-fold and using a small volume of $3 \mu \mathrm{l}$, showed very high antioxidant activity while the same effect was only possible from $300 \mu$ undiluted blueberry or $1000 \mu$ undiluted concord grape [40]. In this study, punicalagin concentrations (1-60 $\mu \mathrm{M})$ showed a significant reduction of ROS levels in Ea.hy926 cell line after stimulation by Ang II $(p<0.001)$.

This study demonstrates that the punicalagin from pomegranate $(1-60 \mu \mathrm{M})$ produced a significant increase in calcium concentration in EA.hy926 cell line after incubation for 24 hours. Polyphenols can affect intracellular $\mathrm{Ca}^{2+}$ store and release it or increase the entrance of $\mathrm{Ca}^{2+}$ through the cell membrane [35]. This suggestion could explain the significant induction of $\mathrm{Ca}^{2+}$ concentration by different punicalagin concentrations in the endothelial cell line $(\mathrm{p}<0.001)$. 
As eNOS enzyme is calcium-dependent, several researchers measured the calcium concentration in EA.hy926 cell line after incubation with different polyphenols. EA.hy926 cell line was incubated for 20 hours with $100-600 \mu \mathrm{g} / \mathrm{ml}$ red wine polyphenols water extract. The experimental dose showed a significant increase in calcium concentration in EA.hy926 cell line, which increased the eNOS protein, level, and showed a significant release of NO [38]. Another study was performed on calcium concentrations in EA.hy926 after incubation with punicalagin and $o$-galloylpunicalagin extracted from Terminalia Calamansanai plant leaves; EA.hy926 cell line, exposed to $50 \mu \mathrm{M}$ of each component for 12 hours produced a significant increase in calcium concentration [41].

Similar to this research outcome, pomegranate juice (50 and $100 \mu \mathrm{M})$ was examined on bovine pulmonary artery endothelial cell line for 24 and 48 hours. The treatment did not show any significant effect on protein expression on eNOS enzyme at any concentration [40]. Chen et al., (2008) examined the effect of punicalagin and $o$-galloylpunicalagin extracted from Terminalia Calamansanai leaves on eNOS expression. Protein expression of eNOS enzyme in bovine aorteic cell line was not affected after incubation for 12 hours with $50 \mu \mathrm{M}$ of punicalagin and $o$ - galloylpunicalagin extracted from Terminalia Calamansanai leaves [41].

In contrast, Leikert et al., (2002) found that red wine polyphenols water extract $(100-600 \mu \mathrm{g} / \mathrm{ml})$ had increased eNOS protein levels after incubation in EA.hy926 cell line for 20 hours [38]. Huang et al., (2004) found a significant increase in protein expression and activity of eNOS enzyme in EA.hy926 cell line after incubation with dihydrocaffeic aicd (caffeic acid metabolite) at different concentrations $(0-200 \mu \mathrm{M})$ for 18 hours. The effect of resveratrol, epigallocatechingallate and epicatechingallate on eNOS enzyme was investigated on EA.hy926 cell line at different concentrations $(0-100 \mu \mathrm{M})$ for 24 hours. The protein level of eNOS enzyme was significantly increased in a dose dependent manner [42]. Edirisinghe et al., (2011) studied the black currant polyphenols $70 \%$ acetone extract on protein expression of eNOS. Different extract concentrations (0.1-10 $\mu \mathrm{M})$ were applied on EA.hy926 cell line for 10 minutes. The treated cells produced a significant increase in eNOS enzyme expression associated with the concentration increase [36]. Different concentration from Hesperetin, type of flavanone present in citrus fruits, $(0.01-10 \mu \mathrm{M})$ and incubated for 1-30 minutes significantly stimulates phosphorylation of Akt, AMPK, and eNOS to produce NO in a concentration- and time-dependent manner in vascular endothelial cells [49].

\section{Conclusions}

All results presented in this study support the proposition that punicalagin is a type of polyphenol that could play a role in reducing the risk of cardiovascular disease. As observed previously, punicalagin incubated with EA.hy926 cells at different concentrations for 24 hours produced a significant inhibition of ACE enzyme activity and increased NO production. Increased NO production was via increased eNOS activity due to an increase in calcium concentration. There was no induction of eNOS enzyme expression observed. This NO level is protected from destruction by ROS through punicalagin scavenging activity. The above findings indicate that punicalagin may be helpful for lowering blood pressure; this could be achieved through dietary intervention or by the production of new anti-hypertensive treatments from a natural product.

\section{Acknowledgments}

Ulfat Omar's studentship was supported by King Abdulaziz University, Jeddah, Saudi Arabia.

\section{REFERENCES}

[1] Heidenreich, P. A., Trogdon, J. G., Khavjou, O. A., Butler, J., Dracup, K., Ezekowitz, M. D., Finkelstein, E. A., Hong, Y., Johnston, S. C., Khera, A., Lloyd-Jones, D. M., Nelson, S. A., Nichol, G., Orenstein, D., Wilson, P. W. \& Woo, Y. J. 2011. Forecasting the future of cardiovascular disease in the United States: a policy statement from the American Heart Association. Circulation, 123, 933-44.

[2] Go, A. S., Mozaffarian, D., Roger, V. L., Benjamin, E. J., Berry, J. D., Borden, W. B., Bravata, D. M., Dai, S., Ford, E. S., Fox, C. S., Franco, S., Fullerton, H. J., Gillespie, C., Hailpern, S. M., Heit, J. A., Howard, V. J., Huffman, M. D., Kissela, B. M., Kittner, S. J., Lackland, D. T., Lichtman, J. H., Lisabeth, L. D., Magid, D., Marcus, G. M., Marelli, A., Matchar, D. B., Mcguire, D. K., Mohler, E. R., Moy, C. S., Mussolino, M. E., Nichol, G., Paynter, N. P., Schreiner, P. J., Sorlie, P. D., Stein, J., Turan, T. N., Virani, S. S., Wong, N. D., Woo, D. \& Turner, M. B. 2013. Heart disease and stroke statistics--2013 update: a report from the American Heart Association. Circulation, 127, e6-e245.

[3] WHO. 2013. Available: http://www.who.int/gho/publications/world_health_statistics /EN_WHS2012_Full.pdf [Accessed 3 October 2013]].

[4] Finegold, J. A., Asaria, P. \& Francis, D. P. 2012. Mortality from ischaemic heart disease by country, region, and age: Statistics from World Health Organisation and United Nations. Int J Cardiol.

[5] Mittal, B. V. \& Singh, A. K. 2010. Hypertension in the developing world: challenges and opportunities. Am J Kidney Dis, 55, 590-8.

[6] Lobo, V., Patil, A., Phatak, A. \& Chandra, N. 2010. Free radicals, antioxidants and functional foods: Impact on human health. Pharmacogn Rev, 4, 118-26.

[7] Sugamura, K. \& Keaney, J. J. F. 2011. Reactive oxygen species in cardiovascular disease. Free Radical Biology and Medicine, 51, 978-992.

[8] Zhang, D. X., Zou, A. P. \& Li, P. L. 2001. Ceramide reduces endothelium-dependent vasodilation by increasing 
superoxide production in small bovine coronary arteries. Circ Res, 88, 824-31.

[9] Himaya, S. W. A., Ngo, D.-H., Ryu, B. \& Kim, S.-K. 2012. An active peptide purified from gastrointestinal enzyme hydrolysate of Pacific cod skin gelatin attenuates angiotensin-1 converting enzyme (ACE) activity and cellular oxidative stress. Food Chemistry, 132, 1872-1882.

[10] Li, H., Junk, P., Huwiler, A., Burkhardt, C., Wallerath, T., Pfeilschifter, J. \& Forstermann, U. 2002. Dual effect of ceramide on human endothelial cells: induction of oxidative stress and transcriptional upregulation of endothelial nitric oxide synthase. Circulation, 106, 2250-6.

[11] Kelly, R. A., Balligand, J. L. \& Smith, T. W. 1996. Nitric oxide and cardiac function. Circ Res, 79, 363-80.

[12] Ignarro, L. J., Buga, G. M., Wei, L. H., Bauer, P. M., Wu, G. \& Del Soldato, P. 2001. Role of the arginine-nitric oxide pathway in the regulation of vascular smooth muscle cell proliferation. Proc Natl Acad Sci U S A, 98, 4202-8.

[13] Napoli, C. \& Ignarro, L. J. 2001. Nitric oxide and atherosclerosis. Nitric Oxide, 5, 88-97.

[14] Aviram, m. \& Dornfeld, 1. 2001. Pomegranate juice consumption inhibits serum angiotensin converting enzyme activity and reduces systolic blood pressure. Atherosclerosis, $158,195-8$.

[15] Clarke, N., E \& Turner, A., J 2012. Angiotensin-Converting Enzyme 2: The First Decade. International Journal of Hypertension, Volume 2012 (2012), Article ID 307315, 12.

[16] Persson, I. A. L., Persson, K. \& Andersson, R. G. G. 2009. Effect of Vaccinium myrtillus and Its Polyphenols on Angiotensin-Converting Enzyme Activity in Human Endothelial Cells. Journal of Agricultural and Food Chemistry, 57, 4626-4629.

[17] Riordan, J. F. 2003. Angiotensin-I-converting enzyme and its relatives. Genome Biol, 4, 225.

[18] Reeves, P. G. \& O'dell, B. L. 1986. Effects of dietary zinc deprivation on the activity of angiotensin-converting enzyme in serum of rats and guinea pigs. J Nutr, 116, 128-34.

[19] Sturrock, E. D., Natesh, R., Van Rooyen, J. M. \& Acharya, K. R. 2004. Structure of angiotensin I-converting enzyme. Cell Mol Life Sci, 61, 2677-86.

[20] Meyers, K. J., Watkins, C. B., Pritts, M. P. \& Liu, R. H. 2003. Antioxidant and antiproliferative activities of strawberries. J Agric Food Chem, 51, 6887-92.

[21] Zhao, C., Giusti, M. M., Malik, M., Moyer, M. P. \& Magnuson, B. A. 2004. Effects of commercial anthocyanin-rich extracts on colonic cancer and nontumorigenic colonic cell growth. J agric food chem, 52, 6122-8.

[22] Havsteen, B. H. 2002. The biochemistry and medical significance of the flavonoids. Pharmacol Ther, 96, 67-202.

[23] Kähkönen, M. P. \& Heinonen, M. 2003. Antioxidant Activity of Anthocyanins and Their Aglycons. Journal of Agricultural and Food Chemistry, 51, 628-633.

[24] Viljanen, K., Kylli, P., Kivikari, R. \& Heinonen, M. 2004. Inhibition of protein and lipid oxidation in liposomes by berry phenolics. J agric food chem, 52, 7419-24.
[25] Ben Nasr, C., Ayed, N. \& Metche, M. 1996. Quantitative determination of the polyphenolic content of pomegranate peel. Z Lebensm Unters Forsch, 203, 374-8.

[26] GIL, M. I., TOMAS-BARBERAN, F. A., HESS-PIERCE, B., HOLCROFT, D. M. \& KADER, A. A. 2000. Antioxidant activity of pomegranate juice and its relationship with phenolic composition and processing. J Agric Food Chem, 48, 4581-9.

[27] Osseni, R. A., Debbasch, C., Christen, M. O., Rat, P. \& Warnet, J. M. 1999. Tacrine-induced Reactive Oxygen Species in a Human Liver Cell Line: The Role of Anethole Dithiolethione as a Scavenger. Toxicol in Vitro, 13, 683-8.

[28] Sudheesh, S. \& Vijayalakshmi, N. R. 2005. Flavonoids from Punica granatum--potential antiperoxidative agents. Fitoterapia, 76, 181-186.

[29] Bindokas, V. P., Jordan, J., Lee, C. C. \& Miller, R. J. 1996. Superoxide production in rat hippocampal neurons: selective imaging with hydroethidine. J Neurosci, 16, 1324-36.

[30] Li, N., Ragheb, K., Lawler, G., Sturgis, J., Rajwa, B., Melendez, J. A. \& Robinson, J. P. 2003. Mitochondrial complex $\mathrm{i}$ inhibitor rotenone induces apoptosis through enhancing mitochondrial reactive oxygen species production. J biol chem, 278, 8516-25.

[31] Grynkiewicz, G., Poenie, M. \& Tsien, R. Y. 1985. A new generation of $\mathrm{Ca}^{2+}$ indicators with greatly improved fluorescence properties. J Biol Chem, 260, 3440-50.

[32] Bradford, M. M. 1976. A rapid and sensitive method for the quantitation of microgram quantities of protein utilizing the principle of protein-dye binding. Anal Biochem, 72, 248-54.

[33] Kapiloff, M. S., Strittmatter, S. M., Fricker, L. D. \& Snyder, S. H. 1984. A fluorometric assay for angiotensin-converting enzyme activity. Anal Biochem, 140, 293-302.

[34] Rey, F. E., Cifuentes, M. E., Kiarash, A., Quinn, M. T. \& Pagano, P. J. 2001. Novel competitive inhibitor of NAD(P)H oxidase assembly attenuates vascular $\mathrm{O}_{2}$ and systolic blood pressure in mice. Circ Res, 89, 408-14.

[35] Martin, S., Andriambeloson, E., Takeda, K. \& Andriantsitohaina, R. 2002. Red wine polyphenols increase calcium in bovine aortic endothelial cells: a basis to elucidate signalling pathways leading to nitric oxide production. Br J Pharmacol, 135, 1579-87.

[36] Edirisinghe, I., Banaszewski, K., Cappozzo, J., Mccarthy, D. \& Burton-Freeman, B. M. 2011. Effect of black currant anthocyanins on the activation of endothelial nitric oxide synthase (eNOS) in vitro in human endothelial cells. J Agric Food Chem, 59, 8616-24.

[37] Hidalgo, M., Martin-Santamaria, S., Recio, I., Sanchez-Moreno, C., De Pascual-Teresa, B., Rimbach, G. \& De Pascual-Teresa, S. 2012. Potential anti-inflammatory, anti-adhesive, anti/estrogenic, and angiotensin-converting enzyme inhibitory activities of anthocyanins and their gut metabolites. Genes Nutr, 7, 295-306.

[38] Leikert, J. F., Rathel, T. R., Wohlfart, P., Cheynier, V., Vollmar, A. M. \& Dirsch, V. M. 2002. Red wine polyphenols enhance endothelial nitric oxide synthase expression and subsequent nitric oxide release from endothelial cells. Circulation, 106, 1614-7. 
[39] Huang, J., De Paulis, T. \& May, J. M. 2004. Antioxidant effects of dihydrocaffeic acid in human EA.hy926 endothelial cells. J Nutr Biochem, 15, 722-9.

[40] Ignarro, L. J., Byrns, R. E., Sumi, D., De Nigris, F. \& Napoli, C. 2006. Pomegranate juice protects nitric oxide against oxidative destruction and enhances the biological actions of nitric oxide. Nitric Oxide, 15, 93-102.

[41] Chen, L. G., Liu, Y. C., Hsieh, C. W., Liao, B. C. \& Wung, B. S. 2008. Tannin 1-alpha-O-galloylpunicalagin induces the calcium-dependent activation of endothelial nitric-oxide synthase via the phosphatidylinositol 3-kinase/Akt pathway in endothelial cells. Mol Nutr Food Res, 52, 1162-71.

[42] Appeldoorn, M. M., Venema, D. P., Peters, T. H. F., Koenen, M. E., Arts, I. C. W., Vincken, J.-P., Gruppen, H., Keijer, J. \& Hollman, P. C. H. 2009. Some Phenolic Compounds Increase the Nitric Oxide Level in Endothelial Cells in Vitro. Journal of Agricultural and Food Chemistry, 57, 7693-7699.

[43] Persson, I. A., Josefsson, M., Persson, K. \& Andersson, R. G. 2006. Tea flavanols inhibit angiotensin- converting enzyme activity and increase nitric oxide production in human endothelial cells. J Pharm Pharmacol, 58, 1139-44.

[44] Chen, J. H. \& Ho, C.-T. 1997. Antioxidant activities of caffeic acid and its related hydroxycinnamic acid compounds. Journal of agricultural and food chemistry, 45, 2374-2378.
[45] Bouchet, N., Barrier, L. \& Fauconneau, B. 1998. Radical scavenging activity and antioxidant properties of tannins from Guiera senegalensis (Combretaceae). Phytotherapy Research, $12,159-162$.

[46] Khan, N., Hadi, N., Afaq, F., Syed, D. N., Kweon, M. H. \& Mukhtar, H. 2007. Pomegranate fruit extract inhibits prosurvival pathways in human A549 lung carcinoma cells and tumor growth in athymic nude mice. Carcinogenesis, 28, 163-73.

[47] Bao, M. \& Lou, Y. 2006. Flavonoids from seabuckthorn protect endothelial cells (ea.hy926) from oxidized low-density lipoprotein induced injuries via regulation of lox-1 and enos expression. J cardiovasc pharmacol, 48, 834-41.

[48] Alia, M., Mateos, R., Ramos, S., Lecumberri, E., Bravo, L. \& Goya, L. 2006. Influence of quercetin and rutin on growth and antioxidant defense system of a human hepatoma cell line (HepG2). Eur J Nutr, 45, 19-28.

[49] Rizza, S., Muniyappa, R., Iantorno, M., Kim, J. A., Chen, H., Pullikotil, P., Senese, N., Tesauro, M., Lauro, D., Cardillo, C. \& Quon, M. J. 2011. Citrus polyphenol hesperidin stimulates production of nitric oxide in endothelial cells while improving endothelial functions and reducing inflammatory markers in patients with metabolic syndrome. J Clin Endocrinol Metab, 96, E782-92. 